\title{
Laboratory simulation experiment on dissolution of limestone under hydrodynamic pressure
}

\author{
Qi Liu $\cdot$ Yaoru Lu $\cdot$ Feng'e Zhang
}

Accepted: 4 March 2013/Published online: 23 March 2013

(C) The Author(s) 2013. This article is published with open access at Springerlink.com

\begin{abstract}
To study the dissolution mechanisms of limestone driven by hydrodynamic reservoir pressure during different storage periods, a simulation experiment on the limestone in a hydropower station of Wujiang River in China was performed. Using a set of specially designed pressure corrosion equipment in an open system, the experiment simulated the dissolution process of limestone under hydrodynamic pressure (0-2.0 MPa) and temperature $\left(15-85{ }^{\circ} \mathrm{C}\right)$. Results show that the amount of dissolution and its rate increase with hydrodynamic pressure and rising temperature, as a result the curve of dissolution rate is obviously changed. In addition, dissolution of carbonate rocks includes both chemical dissolution and physical damage. Differing from the situation under atmospheric pressure, with hydrodynamic pressure rise chemical dissolution, and physical damage increased synchronously ratios tending to be one-to-one. Results show that there is a coupling relationship between chemical dissolution and physical damage leading to a degree of more aggressive dissolution. Microscopic research based on scanning electron microscopy and a mercury injection test shows that the dissolution not only affects the surface of the rock, secondary pore, and mineral form, but also the inner pore
\end{abstract}

Q. Liu ( $\)$ · Y. Lu

Department of Geotechnical Engineering, Tongji University, Shanghai 200092, China

e-mail: liuqi472@163.com

Q. Liu · Y. Lu

Joint Research Center of Urban Environment and Sustainable Development, Ministry of Education, Shanghai 200092, China

Y. Lu · F. Zhang

Institute of Hydrogeology and Environmental Geology, China

Academy of Geological Sciences, Shijiazhuang 050061, China structure, decreasing the permeability and connection among the structural planes of the rock.

Keywords Reservoir - Hydrodynamic pressure . Dissolution of carbonate rocks - Simulation experiment

\section{Introduction}

With the variation of hydrodynamic and environmental characteristics of the water as a result of reservoir water level fluctuation in a karst region, the water-rock interaction of carbonate rock will vary and become more aggressive. It will cause a series of geological problemssuch as dam foundation aging, reservoir leakage, landslides, and karst collapses-due to the physical effect and water-rock chemical interaction (Lu 2003; Song and Shi 1997; Su 2002). Therefore, it is important to study the influence of water-rock chemical and physical interactions on the dissolution characteristics of carbonate rock and evaluate the reservoir's stability and durability.

Results of many experiments on the role of water pressure on carbonate rock corrosion have been reported. Most of the early experiments (Plummer and Busenberg 1982; Busenberg and Plummer 1982) under atmospheric conditions study the dissolution process of calcite as a function of the partial pressure of carbon dioxide $\left(\mathrm{PCO}_{2}\right)$ under $1 \mathrm{~atm}$ and temperature $<100{ }^{\circ} \mathrm{C}$ using the rotating disk, static $\mathrm{pH}$, and free drift methods. Results show that the dissolution rate is closely related to the lithology, structure, reaction solution, temperature, and carbon dioxide partial pressure (Gautelier et al. 1999; Arvidson et al. 2003; Liu and Dreybrodt 2007; Song and Huang 1988; Hu et al. 1997). Simulation experiments under high hydrodynamic pressure and flow conditions mainly concern deep karst development and apply to oil 
exploration or materials engineering and other projects and have been conducted at temperatures up to $300{ }^{\circ} \mathrm{C}$ and pressures up to $20 \mathrm{GPa}$ (Feng and Han 2001; Yang et al. 1995b), Kaufmann and Dreybrodt (2007) studied carbonate rock dissolution kinetics at under-saturation and high pressure. Han (1988) and Jiang et al. (2008) conducted experiments focusing on deep burial carbonate rock dissolution.

Dissolution experiments with carbonate rocks have not been given adequate attention in the supergene and shallow area of a reservoir. Many researchers have approached the subject under atmospheric conditions or mechanical stress loading (Tang and Zhou 1996; Alim 2005; Yang et al. 1995a; Jiang 2008) and the results have not fully revealed the water-carbonate rock interaction mechanisms under hydrodynamic pressure.

This article reports on the simulated dissolution process of carbonate rocks in different periods of reservoir storage with custom designed pressure dissolution test equipment, as well as analysis of the dissolution differences and the mechanism of water-rock chemistry in an open system.

\section{Dissolution experiment}

\section{Experimental samples}

Rock samples were collected from a reservoir dam below the Wujiang River Basin area where Triassic aged Yongning and Yelang series rocks outcrop. The sample locations, the mineral faced, and chemical compositions are detailed below (Table 1). Before the dissolution experiment, samples were cut to dimensions of $20 \mathrm{~mm} \times 20 \mathrm{~mm} \times 40 \mathrm{~mm}$, washed with deionized water, placed inside a drying oven, then weighed, dipped in deionized water for some time, and then the rock samples were placed in the dissolution tube.

Laboratory equipment and methods

Pressure dissolution test equipment was designed to simulate an open system in the supergene zone and shallow area of reservoirs (Fig. 1). The laboratory equipment was made of No. 304 acid resistant stainless steel. During the experiment an automatic compensation valve was utilized to regulate and stabilized the pressure. A conventional reducer and needle valve control the outflow; the temperature controller and sensor automatically control the liquor temperature in the corrosion tube.

First, high-pressure carbon dioxide filled a volume of deionized water in the pressure tank to make the initial carbon dioxide liquor concentration $0.00464 \mathrm{~mol} / \mathrm{L}$ with a $\mathrm{pH}$ of 4.35 at normal temperature. Nitrogen gas filled the gasbag, pressing the carbon dioxide-water liquor with the nitrogen gasbag, which does not allow the liquor and nitrogen to contact, ensuring liquor quality, as the pressure transfer medium. The carbon dioxide solubility increased with the pressure. Each test used the same initial concentration of carbon dioxide-water liquor. During the test, hydrodynamic pressure was controlled at different stages to ensure the certain pressure corresponding to the certain carbon dioxide solubility.

Because dam height in China is generally $<200 \mathrm{~m}$, the maximum water pressure of the experiment was $2.0 \mathrm{MPa}$.

Table 1 Chemical compositions and mineral faced characteristics of rock sample

\begin{tabular}{|c|c|c|c|c|c|c|c|}
\hline \multirow{2}{*}{$\begin{array}{l}\text { Number } \\
\text { of rock }\end{array}$} & \multirow{2}{*}{$\begin{array}{l}\text { Number } \\
\text { of } \\
\text { sample }\end{array}$} & \multirow{2}{*}{$\begin{array}{l}\text { Name of } \\
\text { rock }\end{array}$} & \multirow[t]{2}{*}{ Mineral structure characteristics } & \multicolumn{4}{|c|}{ Chemical compositions (\%) } \\
\hline & & & & $\mathrm{CaO}$ & $\mathrm{MgO}$ & $\mathrm{CO}_{2}$ & $\begin{array}{l}\text { Acid } \\
\text { insoluble }\end{array}$ \\
\hline 1 & $\begin{array}{l}13 \\
14\end{array}$ & $\begin{array}{l}\text { Oolitic } \\
\text { limestone }\end{array}$ & $\begin{array}{l}\text { Oolitic structure, particle size is generally between } 0.5 \text { and } 1 \mathrm{~mm} \text {, } \\
\text { residual sparry cement structure. Oolitic } 60-70 \% \text {, calcite } \geq 90 \% \text {, } \\
\text { dolomite } 7-8 \% \text {. Bedding (massive) structure }\end{array}$ & 53.14 & 1.72 & 42.8 & 0.91 \\
\hline 2 & $\begin{array}{l}21 \\
22 \\
23\end{array}$ & Micrite & $\begin{array}{l}\text { Calcite } 98 \% \text {, iron impurities } 1-2 \% \text {. Mainly composed } \\
\text { of microcrystalline calcite, mostly xenomorphic granular, } \\
\text { smaller particle size, generally between } 0.01 \text { and } 0.03 \mathrm{~mm} \text {, } \\
\text { bedding (massive) structure }\end{array}$ & 53.14 & 0.62 & 41.63 & 3.00 \\
\hline 3 & $\begin{array}{l}31 \\
32 \\
33\end{array}$ & $\begin{array}{l}\text { Oolitic } \\
\text { limestone }\end{array}$ & $\begin{array}{l}\text { Oolitic structure, particle size is generally } 0.5-1 \mathrm{~mm} \text {, accounting } \\
\text { for } 60-65 \% \text {; cement has been the formation of microcrystalline } \\
\text { calcite recrystallization, accounting for } 35-40 \%\end{array}$ & 54.29 & 0.41 & 43.34 & 1.85 \\
\hline 4 & $\begin{array}{l}42 \\
43 \\
44\end{array}$ & $\begin{array}{l}\text { Oolitic } \\
\text { limestone }\end{array}$ & $\begin{array}{l}\text { Round granular or oval-shaped grains multi-oolitic, oolitic center } \\
\text { diamond dolomite crystals, oolitic size is generally } 0.5-1 \mathrm{~mm} \text {, } \\
\text { accounting for } 60-65 \% \text {; oolitic cements are sparry calcite, accounting } \\
\text { for } 25-30 \%\end{array}$ & 54.12 & 1.24 & 42.43 & 0.71 \\
\hline 5 & $\begin{array}{l}51 \\
53\end{array}$ & $\begin{array}{l}\text { Dolomitic } \\
\text { limestone }\end{array}$ & $\begin{array}{l}\text { Granular structure. Rock mainly composed of dolomite and calcite, } \\
\text { the dolomite crystals are euhedral or subhedral, particle size is } \\
\text { generally between } 0.03 \text { and } 0.05 \mathrm{~mm} \text {, uneven distribution, } \\
\text { local more content }\end{array}$ & 36.95 & 10.22 & 38.84 & 10.79 \\
\hline
\end{tabular}


Fig. 1 Structure schematic of pressure dissolution system

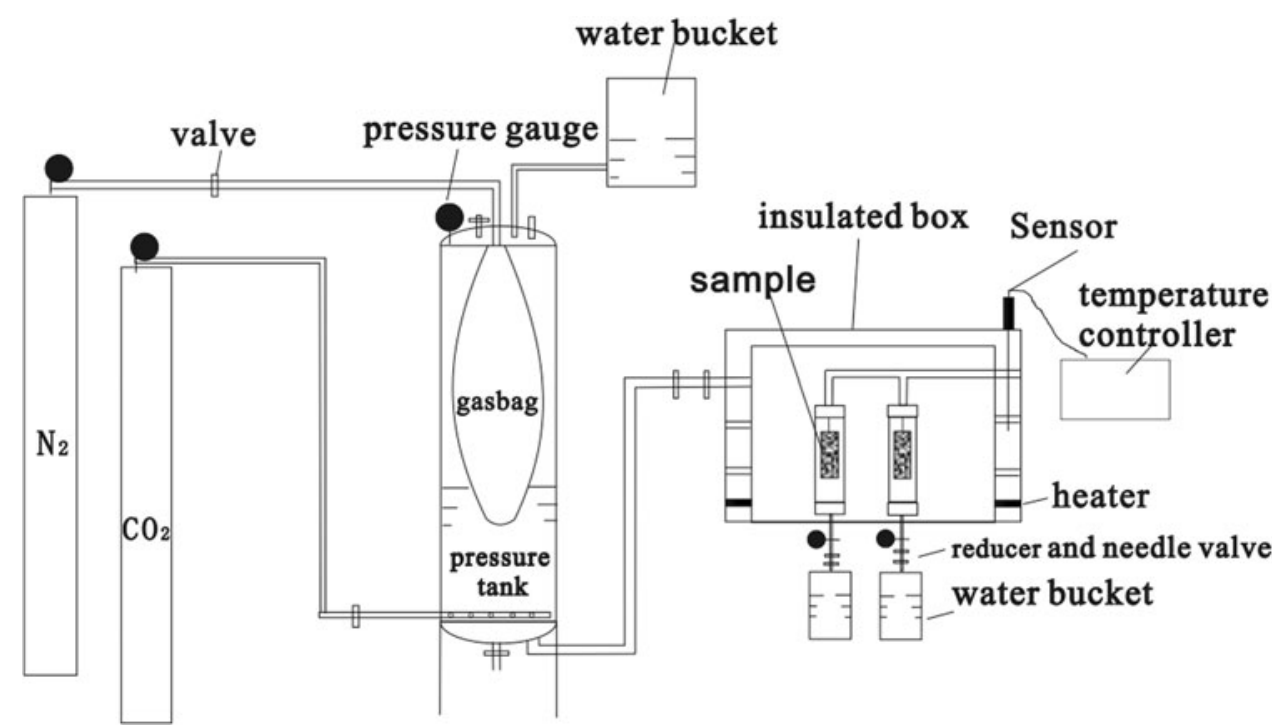

The experiment uses the dynamic pressure balance method wherein the carbon dioxide-water pressure solution continuously flows through the rock sample. During the experiments the flow rate was controlled to $1.5 \mathrm{~mL} / \mathrm{min}$ and time was fixed to achieve total process control. Temperature was automatically controlled by a temperature controller. Studies of the dissolution process of different limestone samples were performed by measuring the total outflow volume and the ion concentration. A collection of dissolution liquor was periodically chemically analyzed. The microscopic character of rock samples before and after dissolution was analyzed by scanning electron microscopy and a mercury injection test method.

\section{Experiments and result analysis}

Hydrodynamic pressure on the dissolution of rock samples

Two hydrodynamic pressure conditions were simulated:

\section{Hydrodynamic pressure increasing}

Considering water level continuously increased in the reservoir impoundment, the experiment used increasing hydrodynamic pressures of $0.1,0.6,1.0,1.6$, and $2.0 \mathrm{MPa}$ on samples $21,51,32$ and 43 for $2 \mathrm{~h}$ at each pressure for a total cycle time of $10 \mathrm{~h}$ (Table 2; Fig. 2). The results show that the carbonate dissolution rates were higher during the initial stage of the experiment and then decreased. When the pressure continued to increase to a certain value, the dissolution rates increased. This was mainly due to the carbonate rock dissolving rapidly as the carbon dioxidewater solution during the initial stage of experiment, the dissolution quantity quickly increased, the dissolved minerals with high-pressure water constantly was taken away. With continued dissolution, the soluble surface minerals were reduced and the rock's surface residues formed an insoluble membrane-like layer of less soluble mineral particles, resulting in a lower dissolution rate. Then, as an open system, carbon dioxide-water solution was constantly added and the hydrodynamic pressure was increased. When the pressure increased to a certain value, the pressure on the membrane-like surface had crushing effect and thus played a role in control. The dissolved calcium carbonate and residual insoluble were constantly leaved by high-pressure water, so that dissolution was aggravated.

In addition, results show that the chemical composition and mineral structures of the rock samples affected the dissolution rate (such as sample 51 compared to samples $21,32,43)$. The dissolution rate increased with calcite content $(\mathrm{CaO})$ of the limestone but decreased with the dolomite content $(\mathrm{MgO})$. This is similar to dissolution under atmospheric pressure conditions ( $\mathrm{Lu} \mathrm{2003).} \mathrm{The}$ difference in experimental results is the impact that high hydrodynamic pressure has on the solubility of calcite which is larger than in dolomite, resulting in an increased difference of the total dissolved amount.

\section{Constant hydrodynamic pressure}

Considering the pressure load on the wall rock and the dam during the reservoir impoundment, the experiment loaded a constant hydrodynamic pressure of $1.5 \mathrm{MPa}$ on samples 31 and 42, and 2.0 MPa on samples 21, 32, and 43. Total cycle time was $168 \mathrm{~h}$. The results showed that, for the same rock source, the degree of carbonate dissolution, the dissolution rate, and changes in the process curve all increased with higher hydrodynamic pressure (Table 2; Fig. 3). 
Table 2 Dissolution experimental results of samples

\begin{tabular}{llllllll}
\hline $\begin{array}{l}\text { Number } \\
\text { of sample }\end{array}$ & $\begin{array}{l}\text { Pressure } \\
(\mathrm{MPa})\end{array}$ & $\begin{array}{l}\text { Temperature } \\
\left({ }^{\circ} \mathrm{C}\right)\end{array}$ & $\begin{array}{l}\text { Surface } \\
\text { area } \\
\left(\mathrm{cm}^{2}\right)\end{array}$ & $\begin{array}{l}\text { Dry weight before } \\
\text { experiment of sample } \\
(\mathrm{g})\end{array}$ & $\begin{array}{l}\text { Dry weight after } \\
\text { experiment of sample } \\
(\mathrm{g})\end{array}$ & $\begin{array}{l}\text { Total } \\
\text { dissolved } \\
\text { amount }(\mathrm{g})\end{array}$ & $\begin{array}{l}\text { Dissolved amount per } \\
\text { unit area }\left(\mathrm{mg} / \mathrm{cm}^{2}\right)\end{array}$ \\
\hline 13 & 1.0 & 15 & 38.88 & 39.08 & 38.73 & 0.35 & 9.16 \\
14 & 1.0 & 15 & 37.02 & 37.87 & 37.53 & 0.35 & 9.34 \\
21 & $0.1-2.0$ & 15 & 41.89 & 45.17 & 44.72 & 0.45 & 10.72 \\
22 & 2.0 & 40 & 42.38 & 45.87 & 44.17 & 1.70 & 40.15 \\
23 & 2.0 & 16 & 41.35 & 44.53 & 44.09 & 0.44 & 10.67 \\
31 & 1.5 & 15 & 39.88 & 41.46 & 40.41 & 1.05 & 26.40 \\
32 & $0.1-2.0$ & 15 & 40.39 & 43.44 & 42.06 & 39.41 & 34.18 \\
33 & 1.6 & $15-80$ & 38.80 & 40.66 & 39.50 & 0.96 & 32.06 \\
42 & 1.5 & 15 & 38.99 & 40.46 & 40.52 & 1.20 & 24.59 \\
43 & $0.1-2.0$ & 15 & 38.40 & 41.72 & 38.48 & 1.16 & 31.28 \\
44 & 1.6 & $15-80$ & 38.13 & 39.64 & 45.36 & 0.31 & 30.31 \\
51 & $0.1-2.0$ & 15 & 40.87 & 45.66 & 47.68 & 0.37 & 7.47 \\
53 & 2.0 & 16 & 42.75 & 48.05 & & 8.54 \\
\hline
\end{tabular}

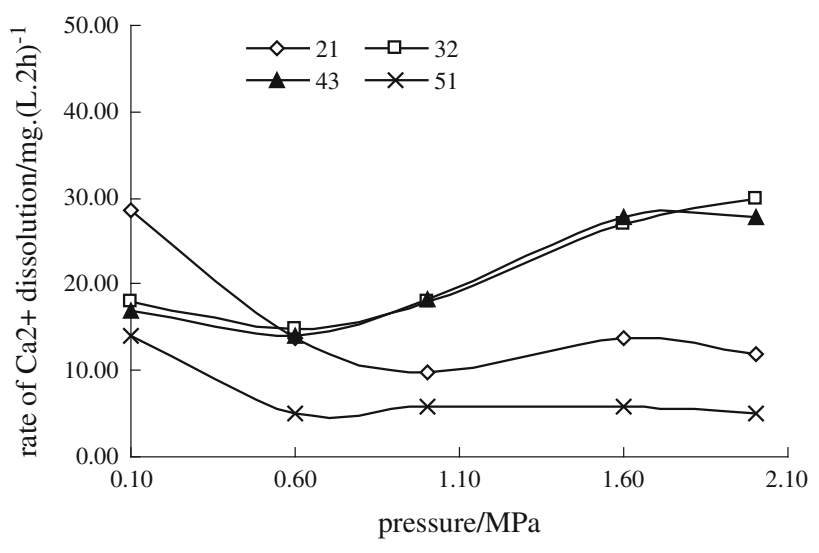

Fig. 2 Hydrodynamic pressure effect on the rate of dissolution

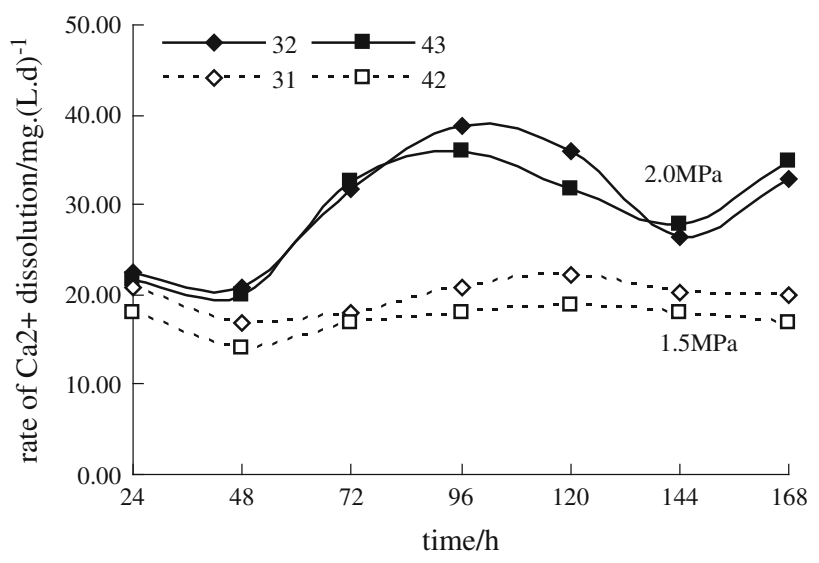

Fig. 3 Comparison of dissolution process curves under different hydrodynamic pressure
Analysis of chemical dissolution and mechanical damage

The sum of the chemical dissolution and mechanical damage is the total dissolved amount during the carbonate dissolution process. The formula is:

Chemical dissolution per unit area:

$K_{C}=\left(C_{\mathrm{CaCO}_{3}}+C_{\mathrm{MgCO}_{3}}\right) / S$

Mechanical damage per unit area:

$$
K_{n}=\left[\left(m_{0}-m_{1}\right)-\left(C_{\mathrm{CaCO}_{3}}+C_{\mathrm{MgCO}_{3}}\right)\right] / S
$$

where $\mathrm{C}_{\mathrm{CaCO}_{3}}$ is the dissolved amount of calcium carbonate (mg), $C_{\mathrm{MgCO}_{3}}$ is the dissolved amount of magnesium carbonate $(\mathrm{mg}), m_{0}$ is weight before dissolution $(\mathrm{mg}), m_{1}$ is the weight of the sample after dissolution $(\mathrm{mg}), S$ is surface area of sample $\left(\mathrm{cm}^{2}\right)$.

Song and Huang (1988) and Hu et al. (1997) report that under atmospheric conditions, chemical dissolution accounts for more than $90 \%$ of the total dissolution, mechanical damage accounts for $2-4 \%$ and mechanical damage is conducive to the development of dissolution. The ratio of chemical dissolution and mechanical damage was significantly different under high hydrodynamic pressures (Table 3; Fig. 4). The chemically dissolved amount is close to $90 \%$ of the total at low pressure-far higher than the amount of mechanical damage. With higher hydrodynamic pressure, chemical dissolution and mechanical damage both increased with a ratio tending toward 1:1. The results show that there is a coupling relationship between chemical dissolution and mechanical damage and this relationship increased the degree of dissolution (Fig. 4). 
Table 3 Different pressure effect on the dissolved amount of samples

\begin{tabular}{|c|c|c|c|c|}
\hline Number of sample & Pressure $(\mathrm{MPa})$ & $\begin{array}{l}\text { Chemical dissolution } \\
\text { quantity }\left(\mathrm{mg} / \mathrm{cm}^{2}\right)\end{array}$ & $\begin{array}{l}\text { Mechanical } \\
\text { damage }\left(\mathrm{mg} / \mathrm{cm}^{2}\right)\end{array}$ & $\begin{array}{l}\text { Chemical dissolution } \\
\text { quantity of total dissolved } \\
\text { amount }(\%)\end{array}$ \\
\hline 14 & 1.0 & 8.30 & 1.030 & 88.93 \\
\hline 31 & 1.5 & 9.52 & 16.88 & 36.06 \\
\hline 42 & 1.5 & 9.21 & 15.38 & 37.45 \\
\hline 32 & 2.0 & 13.83 & 20.35 & 40.46 \\
\hline 43 & 2.0 & 12.98 & 18.30 & 41.49 \\
\hline
\end{tabular}

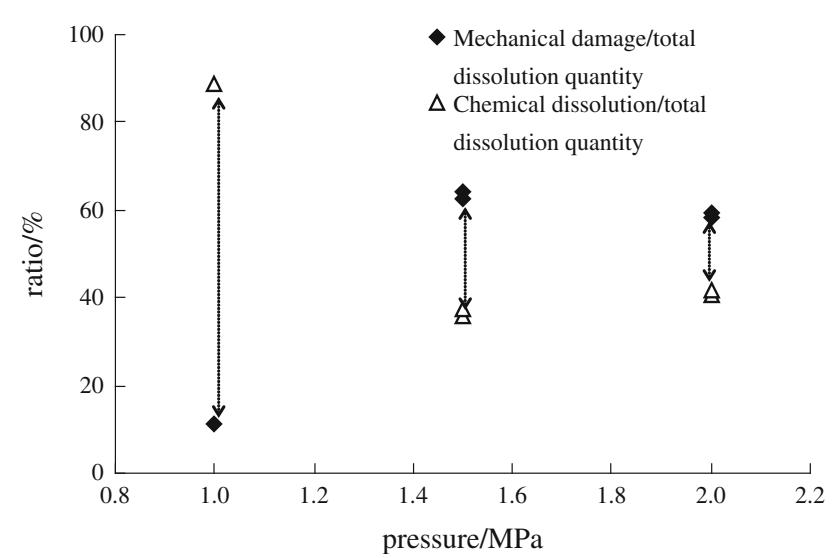

Fig. 4 Hydrodynamic pressure effects on the ratio between chemical dissolution and mechanical damage

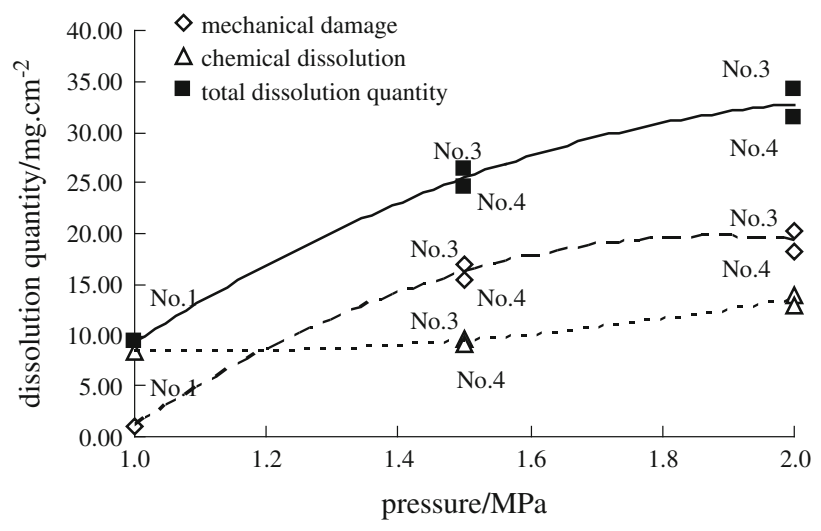

Fig. 5 Hydrodynamic pressure effects on the quantities of chemical dissolution and mechanical damage

The mechanical damage accelerated chemical dissolution mainly due to the larger pressure difference on different parts of the mineral crystals. Mechanical damage reduces the lattice binding; accordingly, the dissolution increased.

In addition, the increased amount of mechanical damage was trending down with a hydrodynamic pressure rise and the chemical dissolution trend was continuously increasing (Fig. 5), indicating a coupling effect exists between

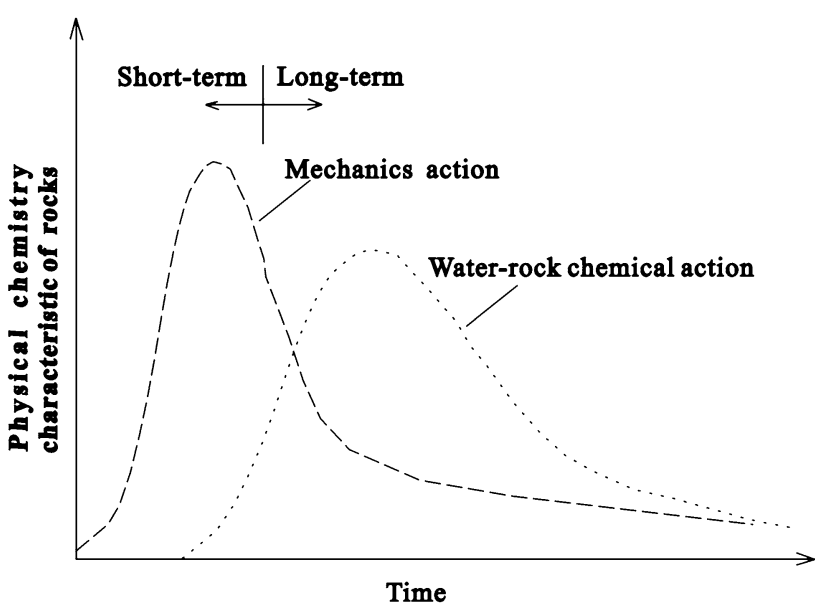

Fig. 6 Schematic diagram of various action effects on physical chemistry characteristic of dam rock mass (Alim 2005)

chemical dissolution and mechanical damage. This also shows that the mechanism of the mechanical load is the controlling factor in the initial impoundment period, but its effect on physical and chemical properties of carbonate rock is short-term. Chemical dissolution has long-term effects and a more complex mechanism. It has a dominant effect on the dam rock mass when time is considered as a factor (Fig. 6).

\section{Surface morphological changes of dissolution}

Contrasting canning electron microscope photos of rock samples before and after dissolution test can be seen:

1. Sample 21 is composed mainly of micrite. After dissolution, minerals rapidly accumulate and small sized grains form. Crystal form was poor and internal cleavage was not developed; therefore, under high hydrodynamic pressure, carbonate seepage dissolution was along the grain boundary, making the dissolution rate higher in the initial dissolution period (Fig. 2). After dissolution test, the separated crystals had a great disparity in size, and were mostly irregular, xenomorphic, and granular. Intact crystals were rare; the crystal 
boundaries of micrite were angular; the sizes of pores and cracks increased; many small dissolution cavities were seen on crystal surfaces; and some holes in the smaller crystals were filled in, indicating that the dissolution of sample 21 was controlled by dissolution along grain boundaries. In addition, because the action of water flowing along the tiny fissures, parts of two walls were expanded and formed dissolution pores in some favorable voids. Along the two micro-fractures seepage water converged to form deep and steep mixture dissolution pores (Fig. 7).

2. Sample 43 is composed mainly of multi-oolitic and rhombohedral dolomite crystals. The high content of calcium in cement, the large surface area, and close water-rock contact points are easily dissolved. The ooids are less susceptible to dissolution: they were protruded with secondary minerals produced (Fig. 8). It is because its unique structure and composition differences favor selective dissolution, forming multifarious dissolution pores and dissolution speeds, which result in a large amount of corrosion. This also explains why the total dissolved amount of sample $43\left(31.28 \mathrm{mg} / \mathrm{cm}^{2}\right)$ is much larger than for sample 21 $\left(10.72 \mathrm{mg} / \mathrm{cm}^{2}\right)$ under the same dissolution experiment conditions (Table 2).

Pore structure changes

According to the principle of least resistance of fluid motion, the reaction solution will flow along the surface of samples into the dissolution tube leading to dissolution during the experiments. However, under the condition of hydrodynamic pressure, whether the dissolution action occurs only on the surface and whether there are influences on the inner pores and cracks or structures can be

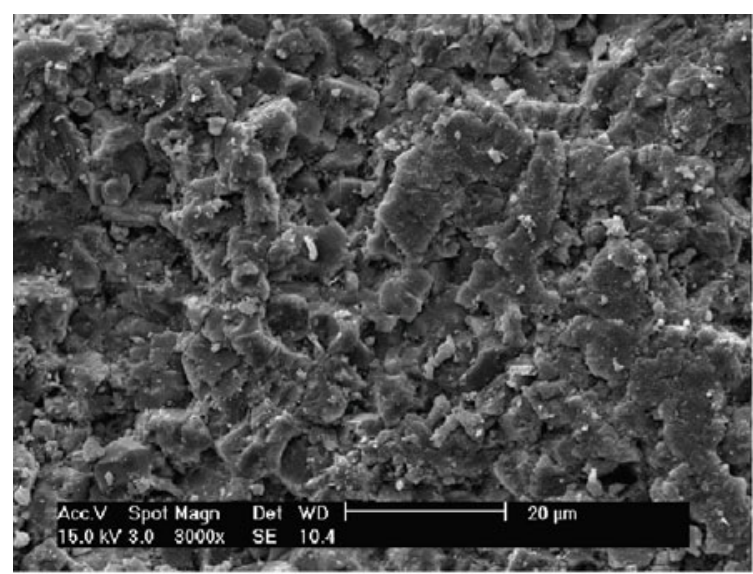

(a)

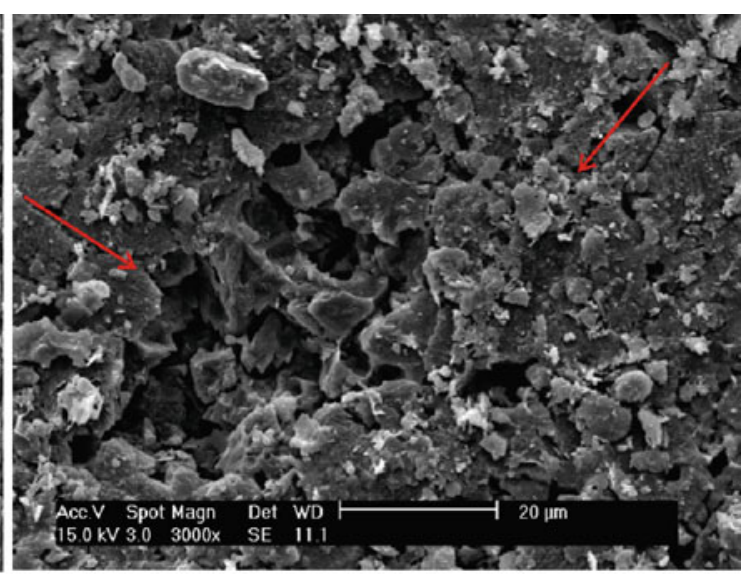

(b)

Fig. 7 SEM photos of sample 21 before and after dissolution test. a Before dissolution test $(\times 3,000)$, b after dissolution test $(\times 3,000$, arrows indicate water flow direction)

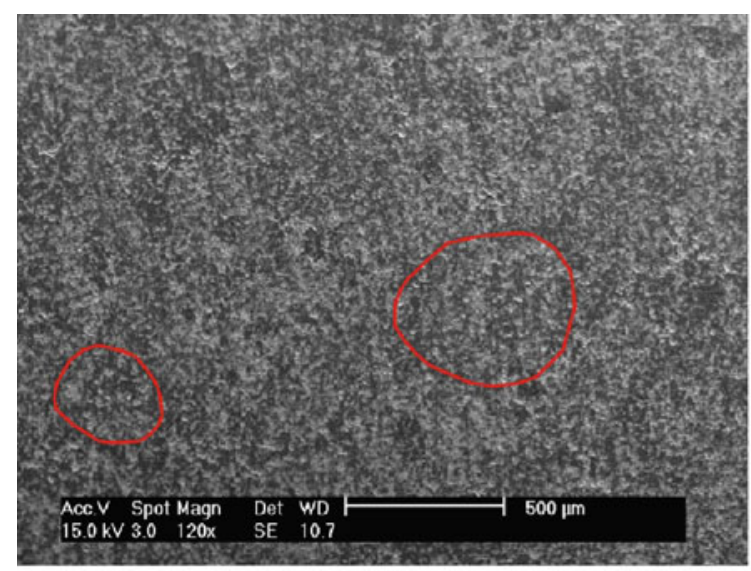

(a)

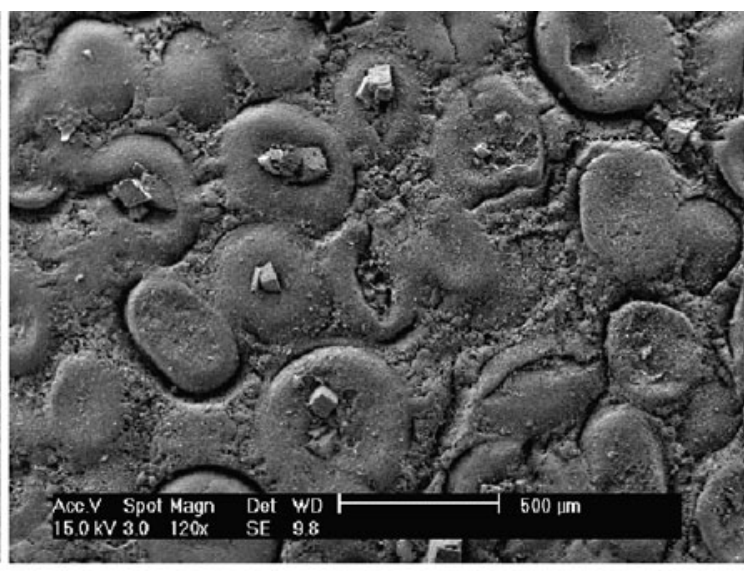

(b)

Fig. 8 SEM photos of sample 43 before and after dissolution test. a Before dissolution test $(\times 120)$, b after dissolution test $(\times 120)$ 
Table 4 Mercury injection test results of rock sample before and after dissolution

\begin{tabular}{|c|c|c|c|c|c|c|c|c|}
\hline $\begin{array}{l}\text { Rock } \\
\text { sample }\end{array}$ & $\begin{array}{l}\text { Porosity } \\
(\%)\end{array}$ & $\begin{array}{l}\text { Permeability } \\
(\mathrm{mD})\end{array}$ & $\begin{array}{l}\text { Density } \\
(\mathrm{g} / \mathrm{ml})\end{array}$ & $\begin{array}{l}\text { Displacement } \\
\text { pressure }(\mathrm{MPa})\end{array}$ & $\begin{array}{l}\text { Characteristic } \\
\text { length }(\mathrm{nm})\end{array}$ & $\begin{array}{l}\text { Median pore } \\
\text { diameter }(\mathrm{nm})\end{array}$ & $\begin{array}{l}\text { Average pore } \\
\text { diameter }(\mathrm{nm})\end{array}$ & Skewness \\
\hline \multicolumn{9}{|l|}{22} \\
\hline Before dissolution & 1.687 & 15.5235 & 2.53 & 0.035 & $35,221.5$ & $341,452.0$ & 4.6 & 11.1633 \\
\hline After dissolution & 0.674 & 1.4366 & 2.49 & 0.165 & $7,545.4$ & $34,073.5$ & 1.9 & 40.4416 \\
\hline \multicolumn{9}{|l|}{42} \\
\hline Before dissolution & 1.233 & 26.9827 & 2.55 & 0.034 & $36,503.0$ & $339,643.2$ & 3.4 & 9.3666 \\
\hline After dissolution & 0.303 & 2.9604 & 2.58 & 0.101 & $12,334.4$ & $340,514.6$ & 0.9 & 30.3086 \\
\hline
\end{tabular}

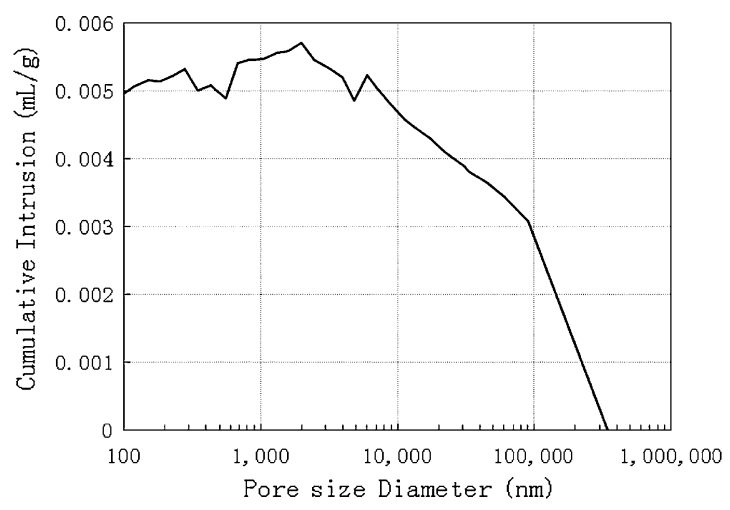

(a)

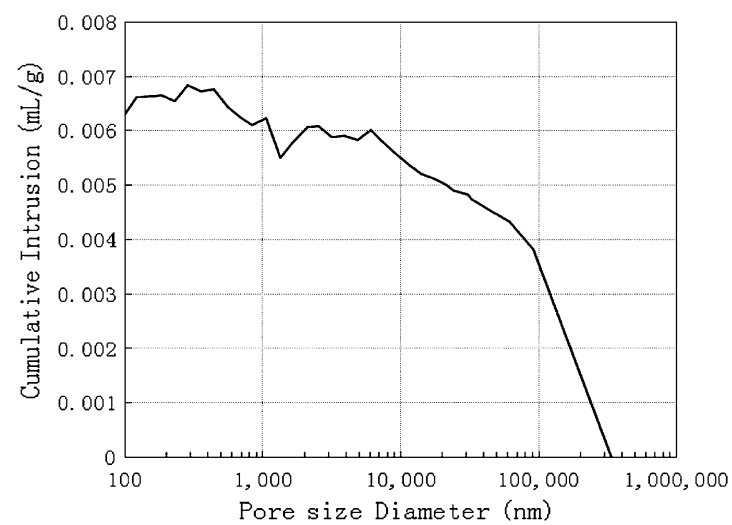

(c)

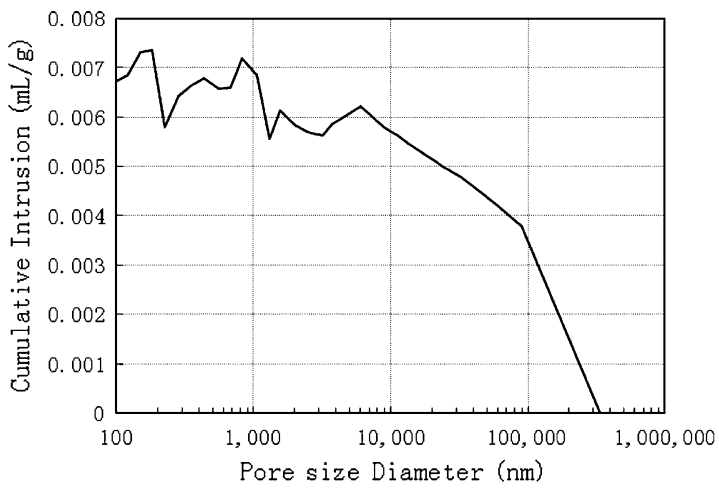

(b)

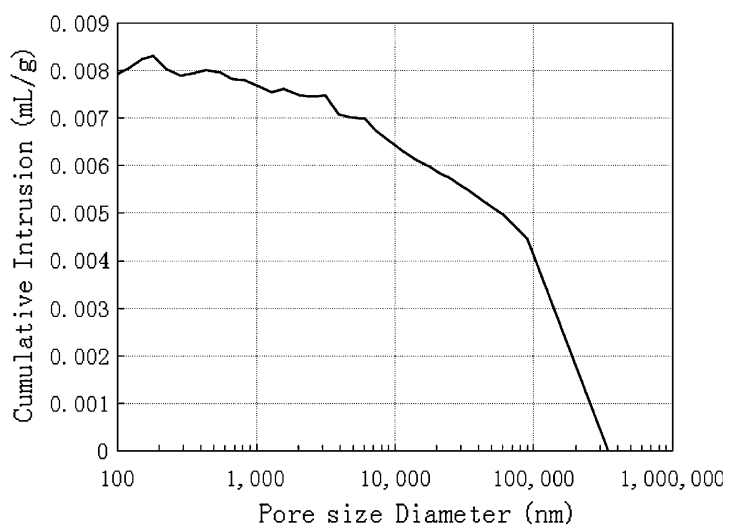

(d)

Fig. 9 Contrastive curves of pore size diameter-cumulative intrusion before and after dissolution. a Before dissolution of No. 22 sample, $\mathbf{b}$ after dissolution of No. 22 sample, $\mathbf{c}$ before dissolution of No. 42 sample, $\mathbf{d}$ after dissolution of No. 42 sample

determined by mercury injection testing. Under hydrodynamic pressure, surface erosion and penetration of corrosion both occurred in sample 42 (Table 4; Figs. 9, 10). Although the penetration corrosion was weak, there are obvious differences in rock pore throats and the pore structure became uneven and discontinuous: the porosity decreased. The increase in the values of displacement pressure and skewness both reflect the weakening of the permeability of the rock. The variations in pore characteristics prove the formation of secondary minerals: the mineral components were dissolved and recombined and filled in the pores. Secondary pores were formed such as intergranular and intragranular dissolution pores. Their development lowered the permeability of rock. In some circumstances, calcareous cement was formed in the pores, thus the strength of the solid medium increased. However, precipitation, transport, and filling of the secondary minerals led to internal restructuring of the rock. The rock structure became uneven. The connection of the weak structural surfaces reduced the strength of the rock. 


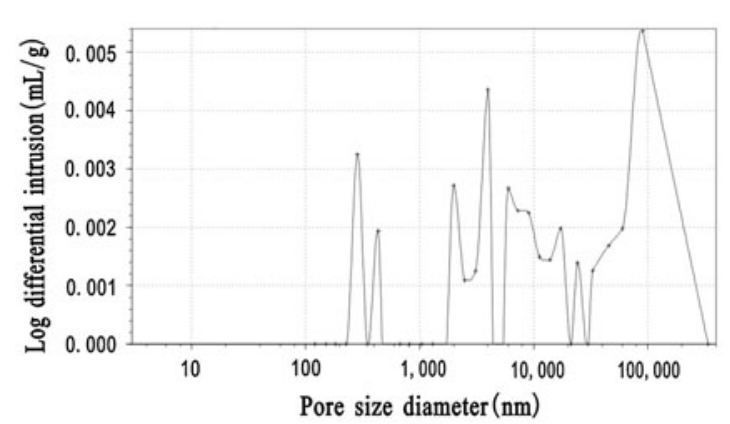

(a)

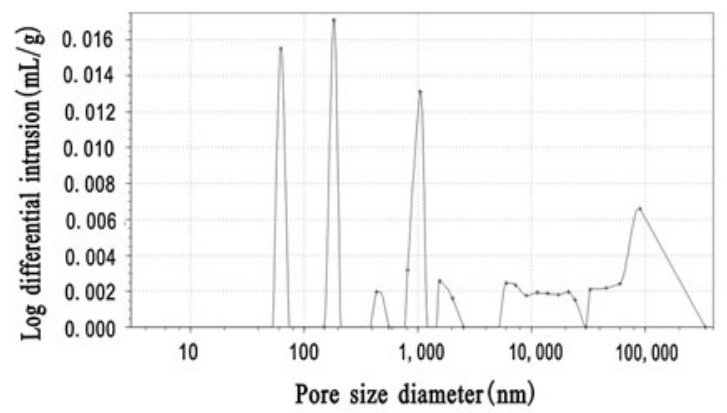

(b)

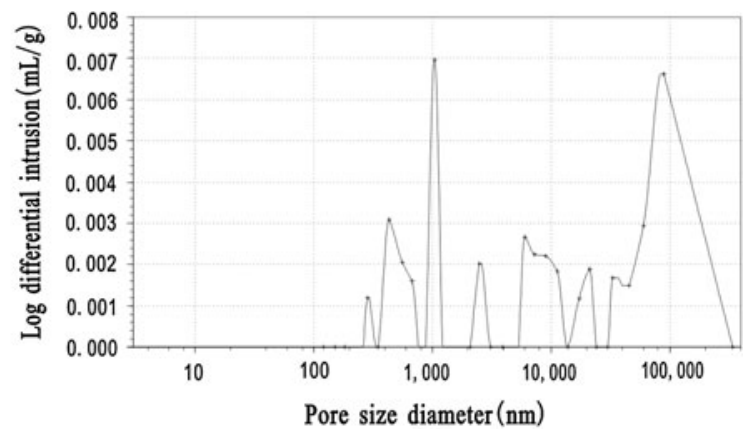

(c)

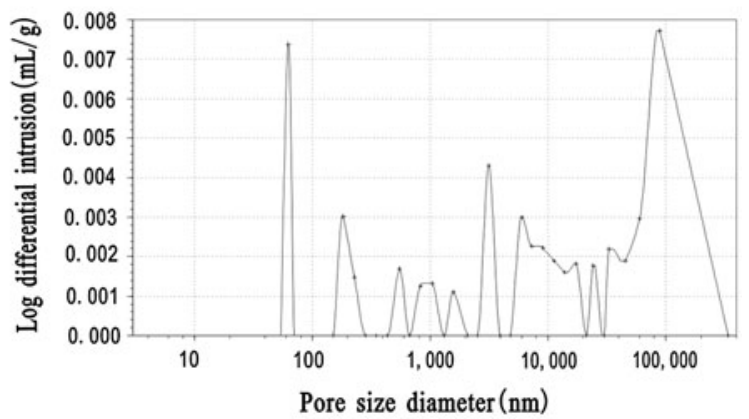

(d)

Fig. 10 Contrastive curves of pore size diameter-log differential intrusion before and after dissolution. a Before dissolution of No. 22 sample, b after dissolution of No. 22 sample, c before dissolution of No. 42 sample, $\mathbf{d}$ after dissolution of No. 42 sample

Fig. 11 Mechanism schematic of pressure effect on carbonate rocks dissolution

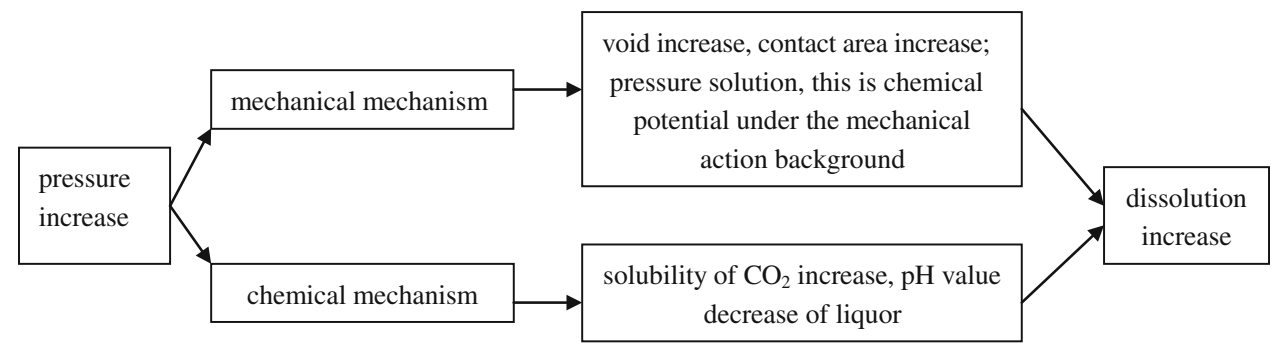

\section{Results and discussion}

The dissolution action under hydrodynamic pressure is a process both controlled by water chemistry and mechanical effects. On one hand, according to Henry's Law, the solubility of carbon dioxide in water is influenced by pressure and temperature. The solubility of gases can be increased by subjecting them to pressure. Hence, there is an obvious difference in dissolution under different hydrodynamic pressure conditions. On the other hand, the dissolution speed or degree depends on the positive relationship between the dissolution rate and effective contact area. Driven by hydrodynamic pressure, water infiltration into the rock structural surface increased the chemical dissolution of carbonate rocks. Meanwhile, the diffusion of minerals on the rock surface into the aqueous solution was enhanced, which contributed to the erosion and the mechanical damage conducive to the development of the chemical dissolution and the chemical dissolution also promoted the mechanical damage. The coupling effect led to the secondary mineralization and pores formed: the pore structure changed and the physical and mechanical properties were influenced (Fig. 11). Therefore, the mechanical effect of dissolution action in carbonate rocks is a continuous accumulation process from qualitative to quantitative changes.

\section{Conclusions}

1. The increase in hydrodynamic pressure may result in enhancement of the dissolution in carbonate rocks. The dissolution rate curve changed considerably with hydrodynamic pressure changes.

2. With hydrodynamic pressure rise, chemical dissolution and physical damage increased synchronously ratios tending to be one-to-one. Coupling effect existing between chemical dissolution and mechanical damage 
and chemical dissolution has a long-term effect in the water-rock interaction.

3. The results of SEM experiments showed that the sizes of pores and cracks increased after dissolution. The crystal boundaries of micrite were angular. It was shown that dissolved pores enlarged and deepened; the ooids of oolitic limestone protruded; and the secondary minerals formed. The influence of hydrodynamic pressure not only occurred on the surface of the rock, penetration corrosion also took place: the internal pore structure changed and secondary pores formed, which decreased permeability and the connection of structural surfaces.

Acknowledgments This work was supported by research Grant 2011BAC09B01 from the National Science and Technology Program in the 12th Five-Year Plan of China: Rehabilitation technology and demonstration of rocky desertification in the karst plateau-gorge, research Grant 20120072120032 from the Specialized Research Fund for the Doctoral Program of Higher Education of China, research Grant 2012KJ011 from the Fundamental Research Funds for the Central Universities of China, research Grant 41072193 from the National Natural Science Foundation of China.

Open Access This article is distributed under the terms of the Creative Commons Attribution License which permits any use, distribution, and reproduction in any medium, provided the original author(s) and the source are credited.

\section{References}

Alim T (2005) Numeric hydro-geo-chemical modeling of dam foundation ageing. Hohai University, Nanjing

Arvidson RS, Ertan IV, Amonette JE, Luttge A (2003) Variation in calcite dissolution rates-a fundamental problem? Geochim Cosmochim Acta 67(9):1623-1634

Busenberg E, Plummer LN (1982) The kinetics of dissolution of dolomite in $\mathrm{CO}_{2}-\mathrm{H}_{2} \mathrm{O}$ systems at 1.5 to $65^{\circ} \mathrm{C}$ and 0 to $1 \mathrm{~atm}$ $\mathrm{PCO}_{2}$. Am J Sci 282(1):45-78

Feng QY, Han BP (2001) Study of hydrogeochemical evolution and water-rock interaction in Renqiu oilfield. China University of Mining and Technology Press, Xuzhou
Gautelier M, Oelkers EH, Schott J (1999) An experimental study of dolomite dissolution rates as a function of $\mathrm{pH}$ from -0.5 to 5 and temperature from 25 to $80{ }^{\circ} \mathrm{C}$. Chem Geol 157(1-2):13-26

Han BP (1988) Study on the simulation of carbonate rock's corrosion. Carsologica Sinica [China] 1:81-88

Hu YB, Bai HB, Zhao HF (1997) Experimental study on limestone dissolution of Taiyuan formation in Xuzhou Xinhe mining area. Jiangsu Coal [China] 3:7-10

Jiang Y (2008) Experimental study of water-sandstone/limestone reaction under triaxial stress [China]. Institute of Earthquake Science China Earthquake Ministration, Beijing

Jiang XQ, Wang SY, Fan M, Zhang JY, Guan HL, Bao YJ (2008) Study of simulation experiment for carbonate rocks dissolution in burial digenetic environment. Pet Geol Exp [China] 12(6):643-646

Kaufmann G, Dreybrodt W (2007) Calcite dissolution kinetics in the system $\mathrm{CaCO}_{3}-\mathrm{H}_{2} \mathrm{O}-\mathrm{CO}_{2}$ at high under saturation. Geochim Cosmochim Acta 71(6):1398-1410

Liu ZH, Dreybrodt W (2007) The kinetics of karst processes and environment [China]. Geological Publishing House, Beijing

Lu YR (2003) Geo-ecology and sustainable development. Hohai University Press, Nanjing

Plummer LN, Busenberg E (1982) The solubilities of calcite, aragonite and vaterite in $\mathrm{CO}_{2}-\mathrm{H}_{2} \mathrm{O}$ solutions between 0 and $90{ }^{\circ} \mathrm{C}$, and an evaluation of the aqueous model for the system $\mathrm{CaCO}_{3}-\mathrm{CO}_{2}-\mathrm{H}_{2} \mathrm{O}$. Geochim Cosmochim Acta 46(6):1011-1040

Song HR, Huang SY (1988) Carbonate and karst. Minerals and rocks [China] 1(3):9-16

Song HZ, Shi XJ (1997) Influence of eluates around dam-sites on seepage stability [China]. Chin J Geotech Eng 5:14-19

$\mathrm{Su}$ WC (2002) Negative effects of cascade hydropower exploitation environmental in the Wujiang basin. Resources and environment in the Yangtze Basin [China] 4(7):388-392

Tang LS, Zhou CY (1996) Analysis on mechanism of permeation and hydrochemical action resulting in failure of loaded rock mass. Acta Scientiarum Naturalium Universitatis Sunyatseni [China] 6:95-100

Yang JJ, Huang SJ, Zhang WZ et al (1995a) Experimental simulation of dissolution for carbonate with different composition under the conditions from epigenesis to burial digenesis environment. Acta Sedimentologica Sinica [China] 4:49-54

Yang RX, Zhou XR, Zhang RH (1995b) Progresses in experimental studies of water-rock interaction. J Grad Sch China Univ Geosci 12(4):419-422 